\title{
Engineering Academics' Strategies of Teaching Mathematical Modelling in Antenna Theory and Design
}

\author{
Vojo George Fasinu ${ }^{1, *}$, Nadaraj Govender ${ }^{1}$, Pradeep Kumar ${ }^{2}$ \\ ${ }^{1}$ School of Education, University of KwaZulu-Natal, South Africa \\ ${ }^{2}$ School of Engineering, University of KwaZulu-Natal, South Africa
}

Received July 25, 2021; Revised September 6, 2021; Accepted October 17, 2021

\begin{abstract}
Cite This Paper in the following Citation Styles
(a): [1] Vojo George Fasinu, Nadaraj Govender, Pradeep Kumar, "Engineering Academics' Strategies of Teaching Mathematical Modelling in Antenna Theory and Design," Universal Journal of Educational Research, Vol. 9, No. 11, pp. 1857 - 1865, 2021. DOI: 10.13189/ujer.2021.091105.
\end{abstract}

(b): Vojo George Fasinu, Nadaraj Govender, Pradeep Kumar (2021). Engineering Academics' Strategies of Teaching Mathematical Modelling in Antenna Theory and Design. Universal Journal of Educational Research, 9(11), 1857 - 1865. DOI: 10.13189/ujer.2021.091105.

Copyright $\bigcirc 2021$ by authors, all rights reserved. Authors agree that this article remains permanently open access under the terms of the Creative Commons Attribution License 4.0 International License

\begin{abstract}
The poor performance of electronics engineering students in modelling their mathematical concepts when learning a practical antenna theory \& design course is of concern. Despite the fact that these future engineers have been taught major aspects of prerequisite mathematics, some still find it difficult to interpret and incorporate it in an antenna theory \& design course. Possible reasons that contribute to conceptual difficulties have been traced to their inability to model and blend mathematical theories, concepts with systems' applications, and also to the disjointedness and lack of explicit teaching and learning approaches implemented in some universities. In this regard, the study takes its point of departure that the modelling of mathematical theories and concepts with clear strategies still remain an important area for engineering educational research and implementation of updated pedagogy. This study critiques the current teaching strategies and competencies of mathematical modelling in an electronics engineering department. It focuses on how engineering academics teach mathematical modelling in prerequisite mathematical courses for preparation of antenna theory \& design. A qualitative approach was adopted to get the naturalistic views of the engineering academics on the strategies of mathematical modelling they use in teaching. Existing mathematical modelling models formed the major theoretical framework that guided the study. The study reports the strategies that are commonly used by engineering academics teaching mathematical modelling in prerequisite mathematical
\end{abstract}

courses related to an antenna theory \& design course. The significant result of the study is a contextual and practical pedagogical mathematical model which can be implemented in teaching and learning antenna theory \& design courses.

Keywords Mathematical Modelling (MM), Antenna Theory \& Design, Didactical-Realistic Model, Teaching and Learning, Mathematical Concepts

\section{Introduction}

Mathematical Modelling in an engineering context is the usage of mathematical concepts in a real-life context, and this could be achieved by applying mathematics in a modelling form [1]. The limited understanding of mathematical concepts and choosing appropriate mathematical modelling (MM) strategies in applying mathematical concepts to industrial applications does impact the productivity of engineering practices. One of the reasons for this is due to the mixed understanding of the meaning of $\mathrm{MM}$ in an engineering teaching and learning context. An observation by one of the researchers notes that when teaching or modelling mathematics together with engineering related topics, mathematics is often considered as a separate subject and not viewed as an applicable and necessary tool in engineering real problem-solving. On this 
note, it is advised that when teaching mathematics in the discipline of electronics/electrical engineering, the strategies of teaching should be in line with the required knowledge needed in the main electronics industry $[2,3]$. It is therefore anticipated that mathematicians teaching electronics engineering students should also simultaneously connect and focus on the industrial applications. Academics who are cognizant of this connection will then ensure that their students will be applying their taught mathematical aspects during their practical operations in industries when they become engineers in a seeming less manner [4]. However, the present teaching approaches in our universities centre mostly on the theoretical modelling of mathematical concepts rather independently of modelling as required in the industry. As a result of this, a chasm has been created between the practical requirements of industry and the theoretical approach by universities - the likely means by which this gap could be bridged is by introducing a relevant approach of teaching $\mathrm{MM}$ in the electronics engineering courses [2]. This idea implies that when teaching mathematics in the department of electronics engineering, mathematicians and engineers should work and plan jointly. It is unfortunate that they do work in independent silos as observed by the researchers, and this has affected students' abilities to appropriately model their mathematical knowledge in engineering applications $[5,6]$. In supporting this argument, a study shows that graduating engineers should be able to demonstrate sound abilities to solve engineering problems, like system design through creative and innovative thinking, possessing abilities to model the mathematical into scientific and technological systems and instruments, execute abilities of analyses and interpretation of mathematical data and during the process of design, and maintain a sound theoretical approach when introducing new technology [2]. A supporting view is expressed by [7] who lament that:

"Attention is diverted away from the physical behaviour of the system and concentrated on the details of the mathematics. Mathematics then becomes a goal in itself and it is easy to forget or ignore the often quite fragile links that were originally set up between the system and its mathematical model. As a result, there can easily be confusion between those results and procedures which relate primarily to the mathematical structure of the model and those which may be interpreted (with care) in terms of the behaviour of the system" (p. 6).

As a result of the above problem, some electronics engineering academics teaching prerequisite mathematics with mathematics concepts related to antenna theory \& design courses find it difficult to change the students' orientation of the appropriate strategies required for practical engineering and it's not easy for universities to find lecturers with dual skills in both fields. Therefore, considering the challenges as observed from engineering academics and coupled with the literature, an appropriate
MM approach for a university was conducted. In achieving this, the study was guided by the research question stated as follows:

$R Q$ How do engineering academics teach mathematical modelling in prerequisite mathematical courses related to an antenna theory and design course?

For further exposure on the state of $\mathrm{MM}$ in the department of engineering, the next section discusses the views of the literature on strategies of MM and concepts and theories as required in prerequisite mathematics.

\subsection{Modelling Mathematical Strategies and Competencies among Electronics Engineering Academics}

Mathematical Modelling (MM) is regarded as a process of blending mathematical theory together with its application and has been a phenomenon of significant impact in the field of mathematics and engineering. However, some engineering academics and students still lack the relevant approaches to follow when modelling it in practical ways. It therefore becomes necessary for the department of electronics engineering to include the method of modelling mathematical concepts explicitly into their teaching and learning [2]. For clarity, the disjunction is not that electronics engineering experts do not use mathematics concepts but the process of teaching and modelling mathematics by the mathematician is different from that of the way electronics engineering academics and students apply their mathematics concepts $[7,8]$. In view of this, [2] suggested that a; "training process of such a professional must take into account an appropriate balance between mathematics, modelling activities coupled with another discipline such as statistics or physics with aim to develop knowledge, understanding the experience of the theory, practice and application of the selected mathematics" (p.197). The ability to apply a professional judgement in mathematics and engineering in order to balance safety and quality, as well as the ability to manage engineering practices applying practical skills of mathematics cannot be overemphasised [2]. Since, the aim of engineering education is to apply mathematics concepts in a practical way when building some engineering equipment, therefore, incorporating a good mathematical modelling approach into the engineering curriculum will go a long way in increasing professional ideas in antenna theory \& design. In achieving this, [9] suggests that a good work place practice among the electronics engineer experts could be attained by adopting some technical skills, and these include: formulation and analysis of mathematical theory, and innovative and creative mind when resolving engineering problems. Also, personal characteristics such as having a self-motivated character, possessing an independent mind, applying their knowledge and understanding the engineering practices as appropriate human and psychological skills necessary when teaching 
MM. Furthermore, some researchers assume that when modelling mathematics together with electronics engineering related courses, in particular, prerequisite mathematics courses, adopting these pedagogical strategies remain non-negotiable. These strategies include: creating the new mathematical model, selecting and adapting the accepted mathematical model, adopting situation-specific methods and procedures in solving mathematical problems and critiquing and analysis of the problem. These approaches will go a long way in assisting the engineers when modelling their mathematical concepts in prerequisite mathematical courses related to an antenna theory \& design course [10].

Similarly, [8] and [11] suggest that engineering academics should adopt some modelling skills when teaching MM in prerequisite mathematical courses. These include the descriptive ability of the modelling process, choosing the physical systems to be described, deciding on the appropriate mathematical structure to be used, adopting the translational rule and the relationship between the equations, and interpreting the modelled result. If these skills are integrated into teaching and learning, a successful mathematical modelling style may increase the competency of the future engineers.

It is common knowledge that engineering students still find it difficult to formulate the mathematical problems from the real world through the process of MM [12], and in improving their MM approaches, their competencies will be enhanced in the workplace. The poor MM pedagogy that still exists may be largely due to the academics' limited knowledge on the process of mathematization when modelling mathematical concepts. Many electronics engineering graduates still claim that most of their mathematical knowledge gained in their universities was not directly relevant in their work place practice $[7,13]$. In seeking a solution to this problem, [14] sees competency as an important process which helps students in structuring real world problems early at university and working with the intention of suggesting possible solutions to the engineering problem. In view of this, the following approaches and skills of MM concepts remain important. These are: formulating skills, problem solving skills which help in manipulation, interpretation skill, analysis, and validating skills. Therefore, when integrating mathematical concepts into the learning of engineering related courses, these pedagogic $\mathrm{MM}$ models remain important to implement and evaluate for their effectiveness. The steps for MM include the physical description of the system, mathematical description of the system (solution model) and synthesising description of a system (system design) [7]. All these steps were further supported by [15] who proposes that during the modelling of mathematical concepts, a critical consideration of some modelling skills, such as, observational skill, modelling methods, mathematical knowledge structure and general knowledge structure among many others remain important. Following the above stated strategies and competencies, it is important to state that all engineering academics teaching prerequisite mathematical courses must possess these in order to move from being ordinary mathematical analysts to modellers - a professional attribute expected from practising engineers.

\section{Theoretical Perspectives of the Study}

The review of the existing theoretical frameworks guiding the teaching of mathematical modelling in engineering related courses confirms the existence of theories and models proposed for teaching and learning [3], [16], [17]. On this note, the didactical mathematical model was judged as being appropriate for interpreting the strategies adopted by the academics at the beginning of teaching the engineering students about the process of mathematical modelling in prerequisite mathematical concepts [14]. This model (didactical model), is a comprehensive representation of the mathematical modelling in a theoretical and empirical insight [16], [17], [18]. It is a model that helps the academics when moving from a transitional phase of modelling using different mathematical modelling styles as suggested below i) understanding the task, ii) simplifying or structuring the task, iii) mathematizing of the mathematical model, iv) working mathematically in resolving the given mathematical problem, v) interpreting of the result of the mathematical model, vi) validating of the final outcome of the mathematical result in a realistic way [18]. While another model reported by Gallegos, Blomhøj and others $[16,20]$ and $[1,21]$ explained some aspects of mathematical modelling for a physical system, which could be regarded as a realistic model, and it addresses the modelling of some mathematical concepts in a real-life situation. Therefore, $\mathrm{MM}$ in a realistic context was further described by Gallegos [16] as a model having three major domains; namely, the pseudo-concrete (imaginative representation of mathematical problems), physical modelling (practical modelling of mathematics in design) and mathematical domains (mathematical usage in real-life stage). All these deal with the integration of appropriate mathematical concepts in engineering context. But it is unfortunate to report that some engineering academics have shifted their focus from the modelling of mathematical concepts, as used by professional engineers, to giving more exclusive attention to the analytical part of mathematics which goes against the aim of the engineering profession [7]. It is on this note that Gómez-Tornero and others [22] suggested that during the teaching of an antenna theory \& design course at theoretical stage, mathematical concepts should be adopted as a tool to link the student's theoretical knowledge to the practical reality of the design. Accordingly, it is essential to use a realistic mathematical model for a real-life situation. In support of this, Blomhoj 
and others further stressed that engineering designers should possess adequate experience on realistic projects that make the use of mathematical modelling as a key tool $[1,16]$. Therefore, to illuminate this point, the proposed realistic model will go a long way in explaining the strategies of modelling mathematics among engineering academics. All these stages were used to validate this study by comparing the modelling approaches of teaching MM in prerequisite mathematics with the data from this study.

\section{Methodology}

The study investigated electronics academics' strategies of modelling mathematical concepts into their teaching of prerequisite mathematics related to antenna theory \& design course. In achieving this, a qualitative research approach was adopted for this study because it assists the researchers in understanding and interpreting the raw data collected from the participants without any other additional views from the researchers $[23,24]$. An interpretive approach was used as the major qualitative approach that helps in considering the theoretical and empirical views of the study due to its advocacy of incorporating the understanding of human actions and meaning rather than a personal view about the research participants [24,25]. This was done using a purposeful sampling procedure in order to select the appropriate group in getting the sample for the study [25], and four engineering academics teaching prerequisite mathematics that are related to an antenna theory \& design course participated in this study. A survey questionnaire and interview guide were constructed and used during the process of data collection, both video and audio tools were used as means of collecting the data. All of them participated in the study stating and explaining their views on the strategies they adopted when teaching prerequisite mathematical courses. The data collected were coded and analysed for themes that emerged (strategies) for effective teaching of prerequisite mathematics for antenna theory \& design. The data, results, discussion the findings are reported next In summary, the data collection process was obtained from the engineering academics teaching the prerequisite mathematical course in the University of KwaZulu-Natal South Africa.

\section{Data, Analysis, Result and Discussion}

This study identified some emergent issues on mathematical modelling in prerequisite mathematical courses related to an antenna theory \& design course offered in department of electronics engineering. The data, results and discussion are separated into two sections: (4.1) Strategies of modelling mathematical concepts in prerequisite mathematics courses and (4.2) Summary on the strategies adopted by prerequisite mathematics academics.

\subsection{Strategies of Modelling Mathematical Concepts in Prerequisite Mathematics Courses}

Four strategies of teaching were discussed by the four academics and are summarised as follows, with snippets of evidence from the survey questionnaires and interviews.

i) Strategy one- Real-life Situational Step. This strategy reports that when teaching prerequisite mathematical concepts, the engineering academics teaching these courses always identify the nature of the mathematical problem to be used before applying those mathematical concepts to real-world situations. This was gathered from the view of the participants teaching the prerequisite mathematics courses when asked to explain how they model their mathematics concepts into their teaching. Gathering from the views of the participant, academic AC3 suggested that; "In order for the students to understand better it is good to first bring the problem into their understanding. Like if you want to model or use mathematics for scheduling or production, you first talk about what is happening in the industry first. You will just bring the process... because they want to work in industries, some of them are already there because their fathers are engineers and they are introducing them to those things already or they might have gone to work as volunteer workers in one industry or the other. Therefore, it is good to first bring to them what is happening, that will arouse their interest that is number one. Two, it opens their mind to what you want to do in mathematics. Then you will now bring mathematics in, by now saying that in order to solve this mathematics problem in engineering or in production company or in scheduling company or in any engineering company you need to bring them to variables. In our own mathematics or in our time we represent each of these machines by variable $X_{1}, X_{2}, X_{3}$ and $X_{4}$ then we represent those people working (personnel) working on those machines by $Y_{1}, Y_{2}$ and $Y_{3}$ then will formulate it as an optimization problem. These are what we teach in optimization or linear programming problem in order to get our solutions. But, first, you must arouse their interest by talking about what is happening in the industries and then linking up with the mathematics. You must first start with the real-world problem or the situation of the real-world problem then come back to the mathematical problem again after you have gotten your solution. You can now say the solution you got $X_{1}, X_{2}$, $X_{3} \ldots \ldots \ldots$ it is only in mathematics that we know it as $X_{1 \text {, }}$ $X_{2}$, and $X_{3}$ but in the real world it is called machine 1 , machine 2 and machine 3. Then linking up the two together and going back to the mathematics in the real world helps a lot for them to understand modelling very 
well" (AC3, interview). In addition to this, he wrote in his questionnaire that: I first teach the needed mathematical principles and then apply these principles to engineering problems. For example, Fourier series and Fourier transform have application to heat equation and Laplace equation which are engineering problems (AC3, questionnaire). From the views of the participant above, one could identify that when teaching prerequisite mathematical courses in engineering context, the academics teaching these courses adopts some mathematical modelling strategies. For academic AC3, these are: First he teaches the principles behind the concept of mathematical concepts, after which he then applies those principles with real life problems. He then identifies the needed mathematical concepts in an industrial context. These steps corroborate with [9] who reaffirms that when teaching mathematical modelling in prerequisite mathematics courses, academics should be able to teach the students abilities to analyse the essential mathematical formulas, apply those formulae and link them with their engineering practice. If they follow this strategy then it will assist the students to greatly improve their mathematics modelling competency as expected in their engineering courses.

ii) Strategy two-Teach maths first then applications. The strategy identifies that when teaching prerequisite mathematical courses among engineering students, a traditional style of teaching mathematics should come first before applying the mathematics principles to real world engineering problems. In view of this, AC1 commented that: "I teach with maths first, then application to real life" (AC1, questionnaire). While another AC3 commented that: "I first teach the needed mathematical principles, and then apply these principles to engineering problems. For example, Fourier series and Fourier transform have an application to heat equation and Laplace equation which are engineering problems" (AC3, interview). Similarly, AC4 reported that: "In mathematics modules, I think they [prerequisite mathematics academics] teach in general base. For example, if I talked about Laplace transformation, they will teach Laplace transform but when I have lectures with the engineering students, I will apply these concepts and then we teach the same mathematical concepts again with the application of the concepts and how they can apply that problem to a particular system to have the electrical details. Like Laplace transform, we use the value in communication system at each block, so we teach in application base" (AC4, interview). In addition to this, the view of the participants reports that the traditional style of teaching mathematics concepts was adopted by some academics in particular, during the teaching of prerequisite mathematical courses. Therefore, AC1 suggested that the teaching and the application of the mathematics concepts have been found to be efficient tools when modelling mathematical concepts in teaching prerequisite mathematical concepts and this is commonly done using the traditional teaching style in mathematics related courses. On the other hand, AC3 suggests that mathematical concepts are being taught while using the principle of real-life application contexts. From the second line of his view, one could argue that Fourier series is being applied when resolving some engineering issues, particularly when resolving engineering problems related to heat. This corroborates with [8], who suggest that some mathematical concepts that are relevant to electronics engineering students are being taught using some traditional teaching styles presented by the academics. The view of AC4 shows that the strategies adopted by the prerequisite mathematics academics when teaching the mathematical concepts were common to the mathematics academics, and this could be regarded as a general based mathematical teaching which does not give adequate room for a concrete and practical modelling approach to teaching and as expected by the engineering department. This goes in line with the view of [8] who reports that mathematics academics do not apply mathematical concepts in an engineering context but they just use calculations and teach the concept without any or little application.

iii) Strategy three - Select components then choose maths models. Some academics argue that the selection of components always goes before mathematical thinking when teaching mathematical modelling in prerequisite mathematical courses. This was found from the view of the academic $\mathrm{AC} 1$ who argued that, "Yes, always model some mathematics concepts during component selection and mathematical thinking" (AC1, interview). Similarly, academic AC3 also responded that: "Yes (Often) adopts mathematical thinking approach (AC3, interview). Following the views of these participants, it could be said that mathematical modelling is perceived as a process of blending mathematical concepts together in an industrial manner with component use and applications and is a strategy that could be classified as ongoing and integrated. Therefore, the acquisition of important and sequential steps in the process and approach should be encouraged in order for an expected better performance in engineering related problem-solving. Also, researchers support the view that when teaching antenna theory \& design related courses, the modelling of mathematics concepts by the academics teaching prerequisite courses remains unavoidable and this has been an essential tool that aids the students understanding in engineering related courses and supporting lecturers to plan for teaching [11].

iv) Strategy four - Appropriate selection of maths concepts. This strategy reports that recognizing the appropriate mathematical concepts required at each stage of modelling mathematical concepts, when teaching some prerequisite mathematical courses remain important. The 
strategy goes a long way in helping the scientists to update their understanding, and assist the students in improving their level of knowledge which is associated with the zone of proximal development of Vygotsky as suggested by Fani and others [26,27].

The view of the academic ACl confirms that critical thinking skills in problem solving must be explicitly taught. Academic AC 1 suggests that, "during the teaching of engineering mathematics, mathematical applications and critical mathematical thinking are necessary skills to be developed" (AC1, interview). He further stressed that "it [the use of a particular strategy] depends on the problem we are working on, when we are working on a particular problem in industry then you need to know what kind of the mathematics you need to apply for this problem. Of course, an expert like a PhD holder or a lecturer knows immediately the type of mathematics to adopt. But a student might not know this, he must read a related problem to what he wants to do and then he will be able to seek out what type of mathematics that is needed. You come to know the needed mathematics by searching out the related problems to what you are doing so that you will be able to know the actual mathematics background that must be researched on in order to solve the practical problem you are doing" (AC1, interview). While academic (AC2) on her part reported that "critical mathematical thinking must be part of the process of learning and mathematical modelling all the time" (AC2, questionnaire). Similarly, AC3 responded that he does model critical thinking. For example, he states that "during engineering mathematics teaching, mathematics application and critical mathematical thinking" (AC3, interview). It seems from academic practice and views that mathematical modelling could be regarded as an efficient and useful tool that assists and directs academics during their planning, teaching, application and mathematical thinking. Reference [11] reaffirms that when teaching mathematical modelling as a course, an engineering academic should be able to teach the students some skills like inquiry skills, fundamental skills, and critical thinking skills alongside with content and when to apply them, in order to move from the level of rote learning to a practical application stage.

\subsection{Summary of the Strategies Adopted by Prerequisite Mathematics Academics}

The results of the study indicate that the strategies adopted by the academics teaching the prerequisite mathematics courses are important to the teaching of mathematics related courses, but some of them are common to the department of mathematics. Some of the strategies adopted when teaching mathematical modelling in prerequisite mathematical courses are as follows: physical identification of the form and nature of the mathematical problems and concepts to be addressed, adopting a traditional teaching style of mathematics problems before applying the mathematics in a real life engineering context, the selection of components to be used in engineering context with the aid of a mathematical thinking style, and detecting and recognising the actual timing of modelling specific mathematical concepts when teaching the prerequisite mathematical. All these have contributed to the process of teaching and learning the prerequisite mathematical concepts taught by the academics in the department of engineering. Gathering from the strategies stated above, it could be argued that the prerequisite mathematical academics adopt strategies that resemble traditional mathematical teaching approach that is common to the mathematical department. Therefore these approaches of teaching mathematical concepts in the department of engineering, if not transformed may produce mathematicians in the department of engineering, which goes against the aim and goal of engineering departments.

The table below gives the strategies adopted by mathematicians teaching MM courses for antenna theory $\&$ design engineering.

Table 1. Strategies adopted by mathematicians teaching MM course for antenna theory \& design engineering

\begin{tabular}{|c|c|c|}
\hline & Teaching Strategy & Example \\
\hline i) & Real-life Situational Step & $\begin{array}{c}\text { Comparing math } \\
\text { variables (X1, X2, X3) } \\
\text { with machines } \\
\text { variables (Y1, Y2, Y3) }\end{array}$ \\
\hline ii) & $\begin{array}{c}\text { Teach maths first and then } \\
\text { applications. }\end{array}$ & $\begin{array}{c}\text { Teaching the calculus } \\
\text { of number, } \\
\text { differentiation and } \\
\text { Fourier series, } \\
\text { geometry and their } \\
\text { application to real-life }\end{array}$ \\
\hline iii) & $\begin{array}{c}\text { Select component and then } \\
\text { choose maths models. }\end{array}$ & $\begin{array}{c}\text { Identifying the } \\
\text { appropriate math } \\
\text { concepts to be used at a } \\
\text { time }\end{array}$ \\
\hline iv) & $\begin{array}{c}\text { Appropriate selection of maths } \\
\text { concepts }\end{array}$ & $\begin{array}{c}\text { Previous math } \\
\text { knowledge acquired } \\
\text { and applying them into } \\
\text { a system design }\end{array}$ \\
\hline
\end{tabular}

From the data and analysis of the study, a model for teaching MM for antenna theory \& design was constructed and also ideas drawn from various models were integrated as well. The diagram below displays a practical model for $\mathrm{MM}$, followed by a brief explanation of each construct that was drawn from the current approach in teaching MM in antenna theory \& design engineering course (see Figure 1). 


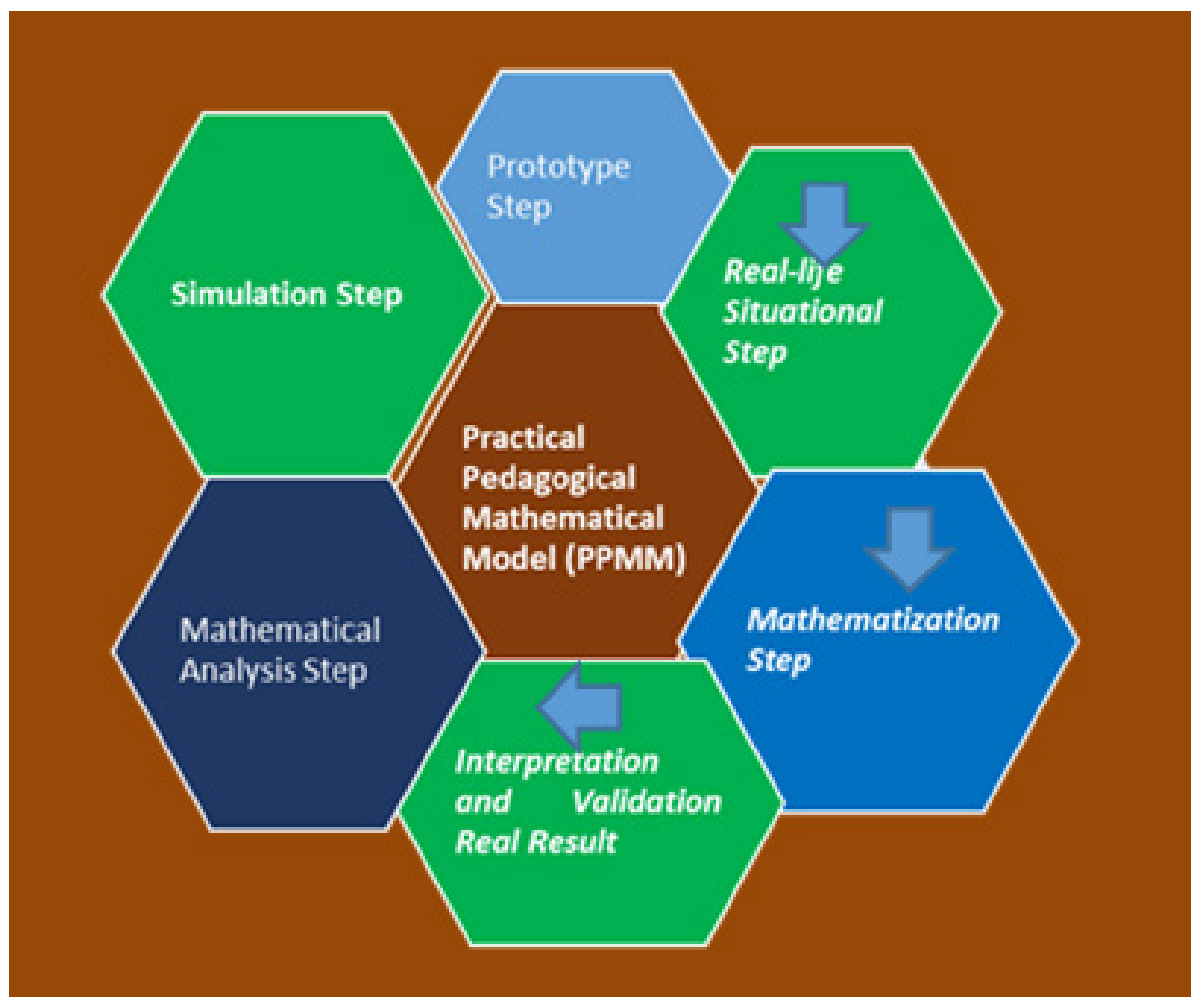

Figure 1. A Practical Pedagogical Mathematical Model (PPMM)

Real-life Situational Step is the first step in teaching prerequisite mathematical concepts that are related to an antenna theory and design course. This section begins with posting of a real-life question which requires a sound mathematical understanding before any progressive step could be made. More so, in teaching the prerequisite maths, the academics teaching the course further adopted a mathematization step which allows the proper selection of the appropriate mathematical concepts which include equations, graphs, theories and other mathematical tools in bringing out the best solution to the mathematical problem [19]. Furthermore, the interpretation and validation of the real result step follow the process of mathematization this gives room for proper interpretation of the calculated mathematical problem in an accurate manner in order to meet up with the expectation of a real-life situation. This is a difficult stage of teaching mathematical modelling, due to the high demand of cognitive thinking and mathematical manipulation required for different levels of problem solving $[3,16]$. In addition to this, another important step is the mathematical analysis, which relates to the practical aspect of $\mathrm{MM}$ as related prerequisite mathematics essential to an antenna theory is selected for the design and helps the engineering academics in analysing the different variables that are involved in the teaching and learning process. This step is done using a realistic teaching approach as found common in engineering design $[3,16]$. In addition to this, the simulation steps help the academics to validate the mathematical variable using different mathematical programs and software, and this is done for the purpose of accuracy and efficiency, and some of these used are excel spreadsheet, MATLAB and vector network analyser among many others [3], [20], [21]. Lastly, the prototype step helps in teaching the actual mathematical tools adopted in explaining the actual mathematical problem in a real-life situation. All these steps eventually generate a didactical-realistic model with minor modifications and use the available data from the study in generating a practical pedagogic mathematical model for teaching antenna theory \& design (PPMM). This model caters to mathematical modelling among engineering academics teaching the prerequisite mathematical concepts that are related to antenna theory \& design courses. This is due to the integration of the traditional teaching style and the realistic teaching approach.

\section{Conclusions}

The results of the study on the engineering academics' strategies of teaching mathematical modelling in prerequisite mathematics courses related to antenna theory and design course indicate that the engineering academics adopt some major strategies when teaching mathematical modelling. The summary of the strategies adopted as stated by the academic includes; bringing in the theoretical mathematics problems and linking them up with the industrial requirements, a comparison and analysis of mathematical variables used in industrial 
machines, linking mathematics variables together with industry ideas, and a description of the mathematical variables adopted during in calculations. In addition to these, it was also confirmed that the formulation of relevant equations from the variables in order to explain the mathematical modelling from some numerical values, modelling mathematics knowledge in real life situations, bringing the problem into the understanding of the students background knowledge and describing the mathematical situations in a real life industrial manner were significant steps. In addition, strategies of application of whole concepts of theoretical mathematics using a didactical-practical teaching method and teaching simultaneously with applications of engineering principles can be adopted when modelling prerequisite mathematical courses. All these strategies are helpful to electronics engineering academics teaching prerequisite mathematical courses related to antenna theory \& design courses.

\section{REFERENCES}

[1] Blomhøj M. "Different perspectives in research on the teaching and learning mathematical modelling," Mathematical Applications and Modelling in the Teaching and Learning of Mathematics, Proceedings from Topic Study Group 21 at the 11 th International Congress on Mathematical education in Monterrey, Mexico, July 6-13, 2009, pp. 1-17.

[2] Palmer M. A., Amat S., Busquier P. Romero, J.Tejada. "Mathematics for engineering and engineering for mathematics," in Educational Interfaces between Mathematics and Industry, Springer, 2013, pp. 185-198.

[3] Soliman H. Y. "Methodology of Teaching and Learning Antenna Theory at Port Said University," in 2019 IEEE Global Engineering Education Conference (EDUCON), 2019, pp. 453-457.

[4] Houston K., Galbraith P., G. Kaiser. ICTMA: "The International Community of Teachers of Mathematical Modelling and Applications-The first twenty-five year," in The first century of the International Commission on Mathematical Instruction (1908-2008), 2007.

[5] Kaiser G., B. Schwarz. "Mathematical modelling as bridge between school and university," ZDM, vol. 38, pp. 196-208, 2006.

[6] Jacobs C. "Transgressing disciplinary boundaries: constructing alternate academic identities through collaboration with 'the other,'" African Journal of Research in Mathematics, Science and Technology Education, vol. 14, pp. 110-120, 2010.

[7] Bissell C., C. Dillon. "Telling tales: models, stories and meanings," For the Learning of Mathematics, vol. 20, pp. 3-11, 2000.

[8] Redish E. F., E. Kuo. "Language of physics, language of math: Disciplinary culture and dynamic epistemology," Science \& Education, vol. 24, pp. 561-590, 2005.
[9] Alpers B. "Studies on the mathematical expertise of mechanical engineers," Journal of Mathematical Modelling and Application, vol. 1, no. 3, pp. 2-17, 2011.

[10] Alpers B. A., Demlova M., Fant C. H., Gustafsson T., Lawson D., L. Mustoe, Olsen-Lehtonen B., Robinson C., D. Velichova. "A framework for mathematics curricula in engineering education: a report of the mathematics working group," Loughborough University, 2013.

[11] Redish E. F., K. A. Smith. "Looking beyond content: Skill development for engineers," Journal of Engineering Education, vol. 97, pp. 295-307, 2008.

[12]Chan E. C. M., Ng D. K. E, Widjaja W., C. Seto. "Assessment of primary 5 students' mathematical modelling competencies" Journal on Science and Mathematics Education, vol. 35, no. 2, pp. 146-178, 2012.

[13]Fasinu V. G. "Undergraduate Electronics Engineering Students' Strategies of Integrating their Mathematical Ideas into their Learning of Physical Electronics," Master's Thesis, University of KwaZulu-Natal, South Africa, 2018.

[14] Maßß K. "What are modelling competencies?," ZDM, vol. 38, no. 2, 113-142, 2006.

[15] Tuminaro J. "A cognitive framework for analyzing and describing introductory students' use and understanding of mathematics in physics," Doctoral dissertation, University of Maryland, USA, 2004.

[16] Gallegos R R. "Differential equations as a tool for mathematical modelling in physics and mathematics courses-A study of high school textbooks and the modelling processes of senior high students," Mathematical Applications and Modelling in the Teaching and Learning of Mathematics, Proceedings from Topic Study Group 21 at the 11th International Congress on Mathematical education in Monterrey, Mexico, July 6-13, 2009, pp. 19-34.

[17] Ferri R. B. "Theoretical and empirical differentiations of phases in the modelling process," ZDM, 38(2), 86-95, 2006.

[18] Xiao X., Xu, H., S. Xu. "Using IBM SPSS modeler to improve undergraduate mathematical modelling competence. Computer Applications in Engineering Education," 23(4), 603-609, 2015.

[19] Van den Heuvel-Panhuizen M., P. Drijvers. "Realistic mathematics education," Encyclopedia of Mathematics Education, 525, 2014.

[20] Balanis C. A. "Antenna theory: Analysis and Design," Wiley \& Sons, 2016.

[21] Honchell J, Miller A. “Antenna Design, Simulation, Fabrication and Test Tailored for Engineering Technology Students," in Proceedings of the American Society for Engineering Education Annual Conference \& Exposition, June 24, 2001, pp. 1-6.

[22] Gómez-Tornero J. I., Cañete-Rebenaque, D., Quesada-Pereira, F. D., A. Álvarez-Melcón. "Interactive Lab to Learn Radio Astronomy, Microwave \& Antenna Engineering at the Technical University of Cartagena (Spain)," International Journal in Online Engineering, 7(1), 10-18, 2011.

[23] Baxter P., S. Jack. "Qualitative case study methodology: 
Study design and implementation for novice researchers," The Qualitative Report, vol. 13, pp. 544-559, 2008.

[24] Cohen L., Manion L., K. Morrison. "Research Methods in Education," Routledge, 2017.

[25] Stake R. R. "Qualitative case studies," in Denzin N.K., Y. S. Lincoln (Eds.), The Sage handbook of Qualitative Research, Sage, 2005, pp. 443-466.
[26]Fani T., F. Ghaemi. "Implications of Vygotsky's zone of proximal development (ZPD) in teacher education: ZPTD and self-scaffolding," Procedia-Social and Behavioral Sciences, Jan 1, 2011, pp. 1549-1554.

[27] Veresov N. "Zone of proximal development (ZPD): the hidden dimension. development, in Ostern, A. \& Heila-Ylikallio, R. (Eds.). Sprak som kultur - brytningar I tidoch rum. - Language as culture - tensions in time and space," Vasa, Vol. 1, pp. 13-30, 2004. 